\title{
AVALIAÇÃO DO PROGRAMA DE CAPACITAÇÃO PARA FORMAÇÃO DE SOCIOEDUCADORES: O ESPORTE COMO POSSIBILIDADE DE ENFRENTAMENTO DA VULNERABILIDADE SOCIAL
}

\author{
Aline Dessupoio Chaves \\ Universidade Federal do Triângulo Mineiro, Uberaba, Minas Gerais, Brasil \\ Heliana Castro Alves \\ Universidade Federal do Triângulo Mineiro, Uberaba, Minas Gerais, Brasil \\ Daniela Tavares Gontijo \\ Universidade Federal do Triângulo Mineiro, Uberaba, Minas Gerais, Brasil
}

\begin{abstract}
Resumo
O esporte educacional pode ser utilizado enquanto estratégias de enfrentamento da vulnerabilidade social, desde que os professores sejam capacitados adequadamente. Este trabalho analisou um programa de capacitação para professores de Educação Física da rede municipal de Uberaba (MG). O estudo contou com 33 professores e estagiários de Educação Física que participaram de um programa de capacitação dividido em 05 oficinas de 04 horas de duração. Antes da primeira oficina, foi aplicado um questionário aos participantes da pesquisa, contendo oito questões abertas, as quais tratavam sobre temas que seriam trabalhados nas oficinas. Ao final da última oficina, o mesmo foi reaplicado para posterior comparação. Dentre os participantes, $85 \%$ assistiram a todas as oficinas, $68,29 \%$ tiveram uma média alteração nos conceitos trabalhados, a maioria teve de três a cinco respostas com alterações positivas, e o conceito que teve mais alteração foi o de causas da vulnerabilidade. Demonstrou-se, portanto, que a formação continuada é uma das melhores possibilidades para a formação docente e para a qualidade do ensino, isso devido à exigência de um trabalho mais contextualizado, participativo e interativo do professor.
\end{abstract}

Palavras-chave: Esporte. Educação Física. Vulnerabilidade.

\section{Introdução}

reconhecimento do esporte como instrumento de socialização
positiva ou inclusão social é mostrado pelo crescente número de projetos esportivos destinados aos jovens das classes populares, financiados por instituições governamentais e privadas. Porém, para que isso aconteça é preciso que haja um resgate de sua função educacional e não apenas de aprendizagem de técnicas e regras.

Conforme a teoria de Bourdieu (1990), na qual a sociedade está dividida em campos (cultural, político, econômico, erudito, entre ou- 
tros), é possível esclarecer a importância que o esporte adquiriu, até mesmo antes do advento da modernidade, por se tratar de uma instância do campo cultural na briga pelo poder com os demais campos. Essa tensão é que sustenta os conflitos sociais, nos quais a intenção é, antes de estabelecer a lei da legitimidade que ditará as normas da conduta social, obter o poder sobre outro campo. Ao narrar a tomada do esporte pelas instituições na modernidade, Bracht (2003) sugere que, nessa relação, ocorre um entrecruzamento de instâncias de interesses de uma dada formação social, no qual se encontram vários níveis: econômico, político, ideológico, cultural. Esses níveis variam em sua dominação de acordo com as diferentes vertentes que o esporte assumiu nessa trajetória: esporte de alto nível (prevalecimento do nível econômico) e esporte escolar/participativo (prevalecimento do nível pedagógico), por exemplo. Isso irá constituir-se como a característica e a função da prática esportiva.

Vivemos em uma sociedade de extremas contradições, em que, de um lado, temos um grande desenvolvimento científico, tecnológico e o avanço da globalização econômica e, de outro, temos o aumento do índice de pessoas que vivem abaixo da linha da pobreza e das desigualdades sociais. Nessa linha de desigualdades encontramos a violação dos direitos humanos básicos, gerando outros fenômenos, como a violência, a drogadição, a prostituição infantojuvenil, e assim por diante (SAGRILLO; BACCIN; BOTH, 2005).

No Brasil, segundo Bursztyn (2000), a existência de pobres é característica desde a colonização, no entanto, o que se apresenta como fato novo é a constatação de que os pobres caem dos patamares da pobreza para os da miséria. Atualmente, mesmo com os indicadores sociais mostrando que os programas governamentais de combate à pobreza têm minimizado essa situação, ainda existem crianças e adolescentes em um contexto de abandono, miséria e violência.

Assim, com base no referencial de Castel (apud GONTIJO e MEDEIROS, 2009), entendemos a vulnerabilidade como uma forma de existência social marcada pela fragilidade, em diferentes intensidades, das relações estabelecidas pelos sujeitos no mundo do trabalho e no contexto social mais próximo. Nessas situações de vulnerabilidade, encontramos sujeitos e grupos familiares induzidos ao desenvolvimento de estratégias que lhe garantam a sobrevivência diária em um contexto de privações econômicas e sociais, que lhes limitam às pos- 
sibilidades de transformações reais em suas vidas, como crianças que deixam de estudar para auxiliar no sustento da família.

Para os indivíduos em processo de vulnerabilidade, Castel (apud GONTIJO e MEDEIROS, 2009) chama a atenção para a ausência de perspectivas e de inscrição em estruturas que sejam portadoras de sentido. Para o autor, o processo de vulnerabilidade e desfiliação não corresponde a uma ausência de relações sociais e, sim, de projetos individuais e coletivos por meio dos quais essas relações ganhem sentido.

Ao se pensar nesse contexto, acredita-se que o profissional de Educação Física em atividade pode ser um profissional importante quando inserido em contextos de vulnerabilidade. Sabe-se que o esporte trabalhado sob a ótica educacional pode possibilitar a elaboração de uma autoimagem positiva para as crianças e jovens, o que já possibilita o fortalecimento interno. Além disso, a figura do professor ganha uma dimensão importante, pois é uma relevante fonte humana para construção de um vínculo saudável que potencialize e fortaleça recursos internos essenciais para o enfrentamento das condições adversas relacionadas à realidade social em que as crianças vivem.

$\mathrm{Na}$ formulação de parâmetros para a formação do socioeducador, elaborado pela Secretaria dos Direitos Humanos, afirma-se que a educação pelo esporte deve empenhar-se em fazer desse recurso um instrumento para a formação humana. Acredita-se, assim, que, para além da formação na prática de uma determinada modalidade esportiva, o esporte deve ser percebido como uma atividade que possibilita uma educação para a vida. Nesse contexto, utilizam-se as atividades esportivas como práticas e vivências capazes de desenvolver na criança e no adolescente em situação de vulnerabilidade as competências pessoais, relacionais, produtivas e cognitivas necessárias para o seu bom desempenho nas relações interpessoais, sociais e no mundo do trabalho (BRASIL, 2006).

O conceito de educação vinculado na Lei de Diretrizes e Bases da Educação Nacional (LDB) corresponde à noção de que educação abrange os processos formativos que se desenvolvem na vida familiar, na convivência humana nas instituições de ensino e pesquisa, nos movimentos sociais e organizações da sociedade civil e nas manifestações culturais. Dessa forma, a essência da ação socioeducativa na qual a Educação Física se insere ao trabalhar em contextos de vulnerabilidade social é a preparação do jovem para o convívio social a partir da 
oferta de um elemento para a constituição de uma rede de suporte social para esse público (BRASIL, 2006).

E, nessa perspectiva, a LDB incentiva a promoção do esporte educacional e apoia as práticas esportivas não formais. Para que se atinjam esses objetivos, é fundamental que o professor seja agente da ação, mostrando-se um profissional competente e principalmente cônscio de suas responsabilidades e que procure o constante aperfeiçoamento pessoal e técnico-profissional, desenvolvendo, cada vez mais, os atributos necessários ao desempenho de suas tarefas.

O esporte emerge como configuração que vem responder ao novo patamar de relações sociais e vai se internalizando com a expressão de um autocontrole que, cada vez mais, representa uma resposta não planejada e em vários níveis, na sociedade de hoje, a um novo equilíbrio entre prazer e restrição e, talvez, uma forma de poder desfrutar de emoções, de um prazer pessoal, coerentemente com a expectativa das sociedades hodiernas e o alto grau de regulamentação imposto (PRONI; LUCENA, 2002).

Segundo Assis (2001), todo esporte, em sua gênese, é um jogo e, como tal, pode ser criado, recriado, reinventado e re-significado, se observarmos as características pessoais de quem o pratica, os objetivos, os espaços e os materiais disponíveis. Assim, o esporte pode ser trabalhado em qualquer idade, basta que seja reinventado (novos objetivos, novas adequações quanto ao espaço, material e regras), objetivando metodologias para ampliar de forma significativa as possibilidades pedagógicas no que se refere ao desenvolvimento e à aprendizagem da criança.

Porém, os aspectos comportamentais, atitudinais e conceituais são fundamentais no que tange à prática pedagógica, de modo a incluir no planejamento das atividades esportivas os objetivos, a metodologia, os conteúdos e também a avaliação, para que o esporte seja ensinado juntamente a valores educacionais. Entende-se por comportamentais quando realiza atividades que possam contribuir para o seu desenvolvimento motor; e conceituais quando é capaz de apreender conceitos concretos e simbólicos de um determinado conteúdo; e atitudinais quando assimila valores, como solidariedade, respeito, coletividade, etc.

O esporte, para Belbenoit (apud BETTI, 1992), pode contribui para reforçar o desenvolvimento de valores como a moral, a ética, a solidariedade, a fraternidade e a cooperação, tornando-se um meio de 
convivência humana. Porém, ele só pode ser educativo quando o educador faz dele, ao mesmo tempo, um objeto e um meio de educação.

$\mathrm{Na}$ abordagem da questão de reconceituação do esporte no país, o esporte deve ser interpretado na abrangência das manifestações definidas por Tubino (1996): esporte-educação, esporte-participação, esporte-performance; mas também chamados por este autor de esporte-educação, esporte-lazer e esporte de desempenho.

O esporte-educação deve ser entendido como a manifestação esportiva que ocorre na escola e que tem por finalidade o desenvolvimento integral do aluno como ser autônomo, democrático e participativo, contribuindo para a cidadania (TUBINO, 1996).

A manifestação esporte-educação consegue abranger desde a infância até a adolescência da população brasileira, além de as maiores possibilidades de ação educativa do esporte incidirem sobre o processo educacional. E essa manifestação deve ser entendida como aquela que ocorre principalmente na escola, mas que pode acontecer em outros ambientes, tendo como finalidade o desenvolvimento integral da pessoa como ser autônomo, democrático e participante, contribuindo para a cidadania.

Segundo Tubino et al. (2007), o esporte-educação é constituído pelo esporte educacional e pelo esporte escolar, o qual utiliza o esporte de rendimento dentro da escola, sendo mais seletivo, mas procurando não perder de vista a formação da cidadania, valorizando o trabalho dentro dos valores éticos (fair play). Pode ser praticado nas escolas, no ensino médio (esporte colegial) e no meio universitário (esporte universitário). Tem como referência o princípio do desenvolvimento esportivo, cujo objetivo é dar condições para que possam aumentar suas potencialidades para a prática do esporte de rendimento; e desenvolvimento do espírito esportivo, o qual contribuirá para o respeito aos códigos, regras, dirigentes e companheiros, além da formação de uma atitude desejável dentro e fora do esporte. Já no esporte educacional, a regra no processo educacional é flexível, para que ocorra a cooperação e não o individualismo. Assim, os alunos podem participar da criação de regras, para que haja uma maior participação sem exclusão.

$\mathrm{O}$ esporte trabalhado no contexto educacional tem por objetivo a formação do educando. Nessa perspectiva, são priorizados valores como a cooperação, a participação de todos e a criatividade, em contraponto à competição exacerbada, à seleção de poucos habilidosos e 
à imposição exagerada dos interesses e desejos do professor, respectivamente. Não só na escola, mas em qualquer espaço social deve-se buscar desenvolver uma relação democrática, respeitosa e responsável de todos os sujeitos, como alunos e professores.

O esporte educacional, também conhecido como esporte-formação, é um direito de todos os jovens, na infância e na adolescência, e compreende as atividades praticadas nos sistemas de ensino e em formas assistemáticas de educação, evitando-se a seletividade e a hiper-competitividade de seus praticantes, com a finalidade de alcançar o desenvolvimento integral do indivíduo e a sua formação para a cidadania e a prática do lazer ativo (TUBINO, 1996).

O esporte educacional, entendido por Barbieri (2001) enquanto meio de educação, no contexto de um processo de educação pelo esporte, permite oferecer alternativas para a formação não só esportiva, mas humana do aluno.

De acordo com Ferreira (1996), o esporte educacional não se trata de mais um esforço metodológico para implementação de práticas esportivas, mas vai muito além disso, trata-se de uma filosofia política que o admite como uma manifestação do esporte que se define a partir de princípios norteadores de uma atividade humana.

Para alcançar fins educacionais, o esporte deve ser trabalhado seguindo seus princípios: princípio da participação; princípio de cooperação; princípio da inclusão; princípio da coeducação; princípio da corresponsabilidade. Dessa forma, promoverá o desenvolvimento global do educando.

Após um breve levantamento, percebeu-se na formação inicial dos sujeitos pesquisados que, durante a graduação, esses conteúdos muitas vezes não são contemplados de acordo com o que as dimensões do esporte (educação, lazer e rendimento) preconizam e que, ao contrário, as disciplinas focam nos valores do esporte institucionalizado e o que acarreta a reprodução dessa dimensão dentro da escola. De tal maneira, surgiu a ideia de oferecer um curso de capacitação para professores da rede municipal que trabalham num programa da prefeitura de Uberaba, em Minas Gerais, oferecido a crianças e adolescentes que estudam na rede municipal de educação, por meio de atividades esportivas e culturais.

Muitas crianças e adolescentes atendidas por esse programa se encontram em estado de vulnerabilidade social, o que justifica a necessidade de um programa de capacitação dos profissionais envolvidos, 
já que percebemos que, na maioria dos cursos de Educação Física, disciplinas que trabalhem conceitos como vulnerabilidade, assim como suas causas e consequências, não estão presentes na matriz curricular.

Sendo assim, fez-se necessária a criação desse programa de capacitação, já que a formação continuada ou a formação em serviço é essencial para que o professor ou, ainda, o estagiário, em sua formação inicial, possam experimentar novos conceitos teóricos nos seus campos de atuação, atendendo às novas demandas que desafiam a sociedade na busca de uma solução para trabalhar com a realidade construída ao longo do processo histórico. Nessa formação em serviço, foi discutida a sua prática para que os conhecimentos necessários para a solução de problemas sejam renovados e seja revitalizada, sempre, a sua práxis.

Portanto, o projeto denominado "Formação de socioeducadores: o esporte como possibilidade de enfrentamento da vulnerabilidade social" realizou um ciclo de capacitação com educadores físicos em prol do desenvolvimento de competências profissionais que valorizem a inclusão social e o protagonismo infantojuventil. Acredita-se que a oportunidade de uma formação continuada que enfoque essas competências propiciam o aprimoramento de uma prática capaz de oferecer suporte social para o desenvolvimento de crianças e adolescentes inseridos num contexto de exclusão e vulnerabilidade pessoal/social, com risco de desfiliação e marginalização na sociedade.

Sendo assim, este trabalho teve por objetivo analisar o programa de capacitação oferecido a professores de Educação Física da rede municipal de uma cidade do interior de Minas Gerais, por intermédio da Secretaria de Esporte e Lazer, onde é desenvolvido o Programa de Educação de Tempo Integral (Proeti), e pela Universidade Federal do Triângulo Mineiro, com a colaboração de professores dos cursos de Terapia Educacional e Educação Física.

\section{Metodologia}

Participaram do estudo 33 professores e estagiários de Educação Física que trabalham no Proeti e que aceitaram participar da pesquisa ao assinarem o Termo de Livre Consentimento. O projeto de pesquisa foi aprovado pelo Comitê de Ética e Pesquisa da Universidade Federal do Triângulo Mineiro sob o número de protocolo 1412. 
O programa de capacitação foi dividido em 05 (cinco) oficinas de 04 (quatro) horas de duração, com os seguintes temas: 1) Vulnerabilidade e implicações para saúde e bem-estar; vulnerabilidade e implicações para a prática educativa; 3) Ser educador - o papel social do profissional de Educação Física; 4) Esporte educacional como estratégia; 5) Inclusão através do esporte.

Antes da primeira oficina, foi aplicado um questionário aos participantes da pesquisa, contendo oito questões abertas acerca dos temas que seriam trabalhados nas oficinas. Ao final da última oficina, ele foi reaplicado, para posterior comparação.

A metodologia adotada nesta investigação é de caráter qualitativo, na qual procurou-se construir as interpretações a partir dos significados expressos pelos participantes do estudo.

O fenômeno investigado trata da compreensão dos conceitos trabalhados ao longo das oficinas. A partir desses significados, buscou-se observar os indicativos de possíveis efeitos dessas ações de capacitação sobre a aquisição de novos conhecimentos em relação aos conceitos contemplados em cada temática.

Essa opção metodológica permite, de acordo com Minayo (1998), penetrarmos o mundo dos significados das ações e relações humanas - que é um lado não perceptível e captável em equações, médias e estatísticas.

O conjunto das unidades de significados foi cuidadosamente lido e analisado e, dessa forma, permitiram que fossem feitos agrupamentos de ideias que se aproximassem e que vieram constituir-se nas categorias de análise. As respostas das questões dos questionários iniciais e finais foram lidas na íntegra, comparadas e avaliadas em termos de qualificação de mudança que revelassem o processo de aprendizagem do professor após o curso ministrado. De acordo com a leitura das respostas, as pesquisadoras registraram separadamente suas percepções em termos de inclusão de novos conceitos ministrados ou mudança na percepção da realidade social do público atendido que foram ou não absorvidos pelos professores. Assim, quando cada participante demonstrava alteração de conceito ou percepção, em termos de qualificação de mudanças coerentes com a proposta do curso, em uma ou duas questões, classificou-se como baixa alteração positiva; de três a cinco questões, como média alteração positiva, e de 6 a 8 questões, como alta alteração positiva. 
Dessa forma, os dados coletados foram agrupados por categorias e transformados em gráfico e tabela para análise quantitativa dos resultados.

Para a análise quantitativa, foi usada a estatística descritiva, calculando média e desvio padrão por meio do programa estatístico SPSS 13.0.

\section{Resultados}

Dentre os participantes, $85 \%$ assistiram a todas as oficinas e apenas $2,57 \%$ estiveram presentes em apenas uma delas.

Em relação aos temas de cada oficina, o conhecimento dos sujeitos foi investigado por meio das oito perguntas do questionário: 1) O que é vulnerabilidade? 2) Quais as causas da vulnerabilidade? 3) Quais as consequências da vulnerabilidade? 4) Existe relação entre vulnerabilidade e esporte? 5) Existe relação entre vulnerabilidade, saúde e bemestar? 6) O que é esporte educacional? 7) Como o esporte pode proporcionar mudanças? 8) Quais as estratégias de inclusão?

Em relação ao questionário aplicado antes da primeira oficina e o aplicado após a última, verificou-se que, ao se comparar as respostas dadas pelos participantes, $68,29 \%$ tiveram uma média alteração positiva nos conceitos trabalhados nas oficinas (mudança qualificada positivamente em relação a conceitos e percepção do professor); $19,52 \%$ tiveram uma baixa alteração; $14,64 \%$, alta modificação e nenhum participante apresentou nenhuma modificação, de acordo com a Figura 1.

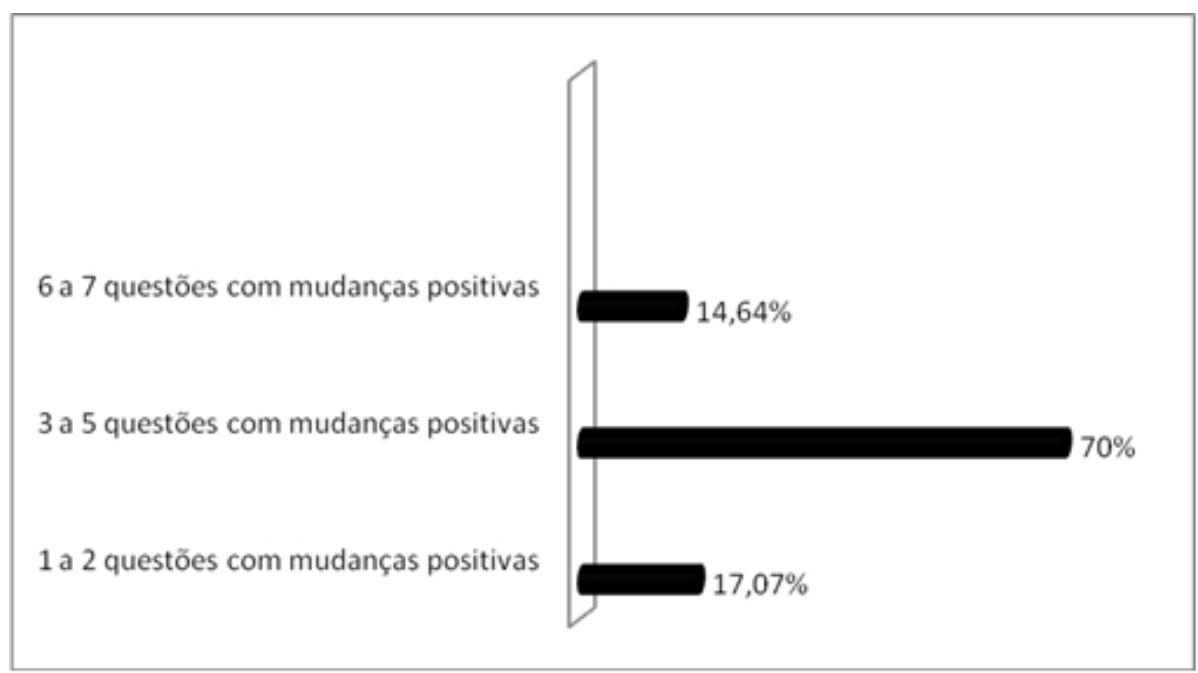

Figura 1: Modificações nos conceitos entre a primeira oficina e a última 
Isso pode ter relação com algumas questões como o ambiente desconfortável, em virtude do calor e claridade para ver os slides e filmes trabalhados, falta de local apropriado para as oficinas e, ainda, a conversa dos participantes durante algumas oficinas, não permitindo que alguns conceitos fossem bem trabalhados.

A Figura 2 retrata a relação entre as mudanças positivas de conceitos trabalhados e a carga horária assistida das oficinas, demonstrando que a maioria dos participantes assistiu a todas as oficinas e tiveram de três a cinco respostas com alterações positivas. O índice de maior quantidade de alterações positivas nas respostas foi daqueles que participaram de todas as oficinas.

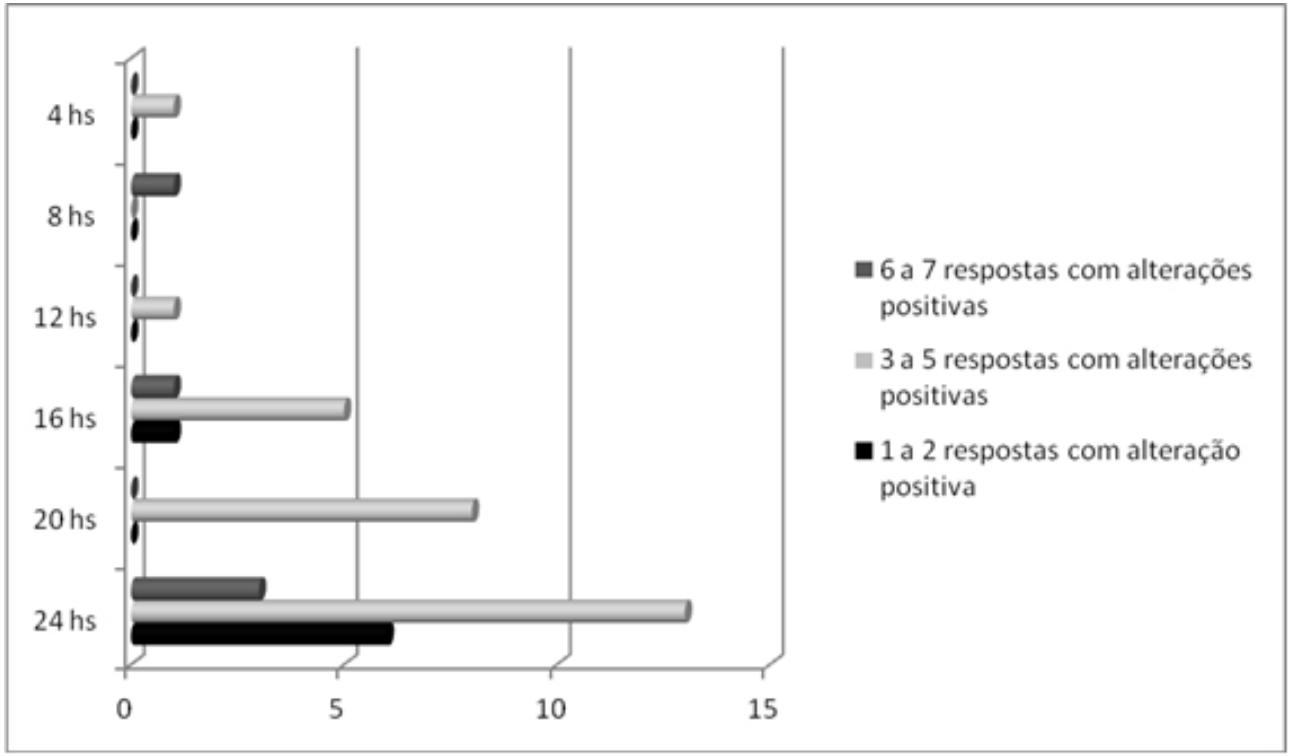

Figura 2: Relação de mudanças positivas de conceitos e carga horária frequentada

A formação permanente de professores está intimamente vinculada à visão que os professores têm de si mesmos e do papel social da Educação Física. Para que se possa compreender como e de que se constituem as iniciativas de formação permanente que são oferecidas aos docentes, é preciso entender que cada uma delas traz em si uma concepção diferenciada do papel do professor (GÜNTHER; MOLINA NETO, 2000).

A Figura 3 demonstra que os conceitos que tiveram maiores alterações positivas foram, em ordem crescente, causas de vulnerabilidade e estratégias de inclusão; possibilidades de mudanças; vulnerabilidade; vulnerabilidade e esporte; vulnerabilidade, saúde e bem-estar; e, por último, consequências da vulnerabilidade. 


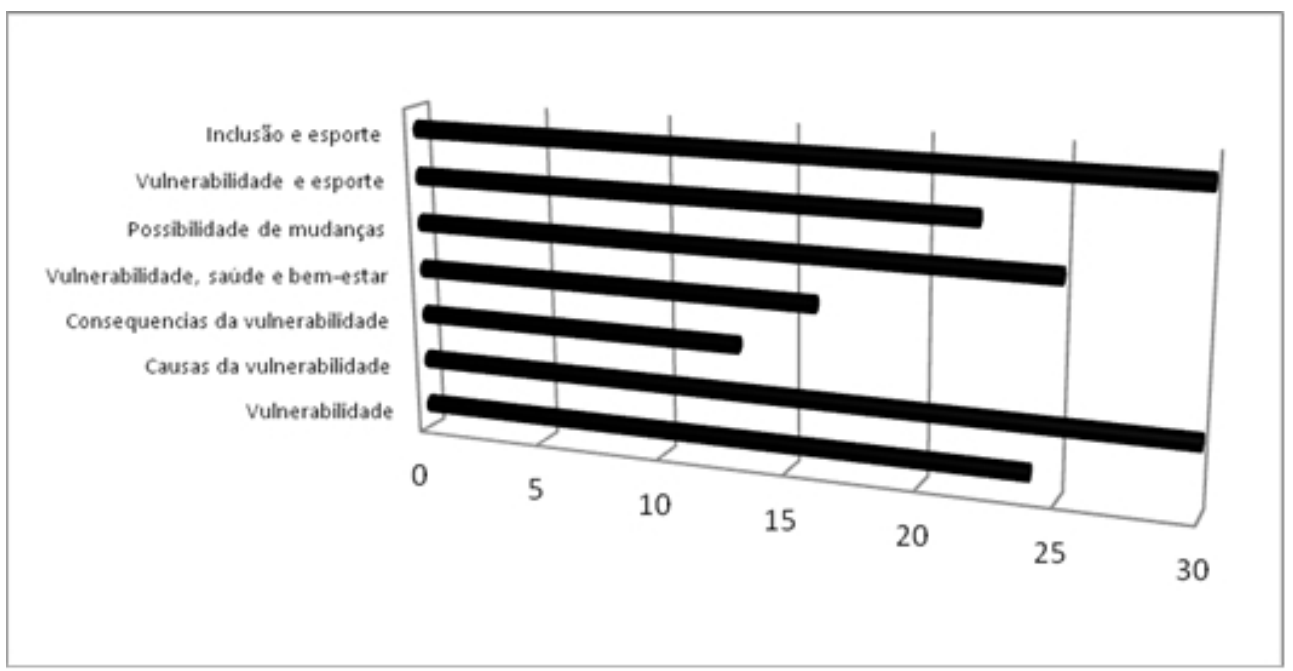

Figura 3: Questões em que ocorreram maiores alterações positivas de conceito

Os conceitos provindos de outras áreas do conhecimento, como sociologia e saúde, geralmente não são oferecidos nos cursos de graduação em Educação Física. Foram aqueles que, inicialmente, os participantes apresentaram maior dificuldade para se expressarem no primeiro questionário. Em contrapartida, foram aqueles que obtiveram uma maior alteração positiva, demonstrando a aquisição de conceitos e a qualificação da discussão desses conceitos na área da Educação Física, junto à prática profissional.

A concepção predominante de currículo dos cursos de graduação ainda equivale a uma listagem de disciplinas que se configura por meio da grade curricular. Dessa forma, questões como a fragmentação do saber e o distanciamento da realidade social são de extrema relevância quando tratamos da formação de professores. As licenciaturas, de um modo geral, vêm atravessando uma crise profunda. A perda de importância da formação pedagógica em detrimento de uma formação mais técnica, juntamente à crescente desvalorização do magistério, transformaram as licenciaturas em cursos menos importantes na hierarquia da universidade e no contexto social. Esse fenômeno, ainda que possa ter características próprias e uma dimensão maior no Brasil, não é restrito à nossa realidade (GÜNTHER; MOLINA NETO, 2000).

Para Esteve (1995), ainda que os futuros professores estejam bem preparados no que se refere aos conteúdos com os quais trabalharão nas escolas, falta-lhes a compreensão sobre a importância do seu papel na organização do trabalho pedagógico e da própria dinâmica da aula em si. Esse período de formação inicial deve propiciar-lhes a capaci- 
dade de identificar e superar problemas na organização do trabalho pedagógico e de tornar acessíveis a todos os alunos os conteúdos de ensino.

A formação inicial não é suficiente para assegurar um trabalho de qualidade. Conforme Hargreaves (2000), essa formação inicial é apenas o primeiro passo para a formação docente contínua. A educação é um conceito amplo de ensino, é um processo continuado de aprendizagem que não se encerra ao final de uma graduação ou de uma pósgraduação, é um processo para toda a vida. Em contrapartida, Demo (2000) assinala que a maioria dos professores não possui o hábito de aprender sistematicamente, pois internalizaram a ideia de que já aprenderam o que tinham de aprender, como se o seu ofício se resumisse simplesmente a ensinar, e ao educando, apenas aprender.

É imprescindível que o professor mantenha-se atualizado, flexível às mudanças e que continue permanentemente sua formação. Terá, então, como principal função: aprender, inovar, diversificar, rever conceitos, etc., para que possa atender às necessidades educacionais escolares, na melhora da qualidade da educação brasileira. Em tempos de globalização, o acesso às informações é muito rápido. O professor necessita qualificar-se constantemente para tentar acompanhar esse processo de mudança (NÓVOA, 1997).

A capacitação em exercício pode contribuir em diversos momentos se trabalhada reflexivamente para que a personalidade profissional docente e a rotina de ação sejam melhor alicerçadas, com uma fundamentação didático-pedagógica em consonância com a atualidade e com a sua área de atuação. Ao mesmo tempo em que promove um (re)pensar e (re)construir coletivo do próprio ambiente de trabalho (SOUZA, 2006).

\section{Considerações finais}

Percebe-se que, em virtude das circunstâncias estruturais em que aconteceram as oficinas, o curso de capacitação teve um resultado positivo para a maioria dos participantes, que, no decorrer de uma atividade para outra, demonstrava maior interesse e participação.

Em alguns casos, em relação aos conceitos trabalhados, alguns não tiveram alterações tão positivas porque estes, na verdade, já eram conceitos conhecidos pelos participantes e, dessa forma, não se alterou, e em menor número foram aqueles que tiveram um baixo enten- 
dimento dos temas abordados.

Pelos depoimentos dados ao final do último questionário, percebeu-se que o programa de capacitação para formação de socioeducadores foi realmente válido na medida em que despertou a reflexão dos profissionais envolvidos no programa Proeti, e ainda trouxe uma visão mais abrangente de estratégias para auxiliarem no trabalho diário junto a crianças e adolescentes em contextos de vulnerabilidade.

Os resultados da pesquisa demonstram que a formação continuada vem a ser um importante momento na formação docente e, respectivamente, na qualidade do ensino, isso devido à exigência de um trabalho mais contextualizado, participativo e interativo do professor. Ao expor suas angústias, problemas e receios com os demais colegas, estão favorecendo o diálogo, oportunizando a troca de experiências, gerando a construção de novos saberes usados na prática pedagógica, o que concorda com Tardif e Lessard (2004), ao ressaltarem que as pessoas são a "matéria-prima" do processo do trabalho interativo e o desafio primeiro das atividades.

Assim, a formação continuada deve acontecer no sentido de possibilitar ao professor um trabalho contextualizado, participativo e interativo, no qual ele possa expor, debater suas angústias, problemas, receios e discutir com seus colegas, favorecendo o diálogo, oportunizando a troca de experiências, gerando a construção de novos saberes que serão usados no dia a dia da prática pedagógica.

Os professores precisam sensibilizar-se para as enormes carências de sua formação, reconhecendo, desse modo, que há necessidade de continuar investindo na formação profissional constantemente.

Evaluation of training program for socio formation: the sport as a chance to confront social vunerability

\begin{abstract}
The sport education can be used as a coping strategy of social vulnerability, provided that teachers are adequately trained. This work analyzed a training program offered to teachers in Physical Education from Uberaba - MG. The study included 33 teachers and Physical Education trainees who participated in a training program which was divided into 05 workshops of 04 hours. Before the first workshop, a questionnaire was administered to research participants, containing 08 open questions about the topics to be worked in the workshops. And at the end of the last workshop, it was reapplied for comparison. Among participants, $85 \%$ attended all the workshops, $68.29 \%$ had a mean change in learning concepts, most had 3-5 with positive responses, and the concept that had the most change was the cause of vulnerability. This showed that continuing education is one of the best opportunities
\end{abstract}


for teacher training and the quality of education respectively, that due to the requirement of a more contextual, participatory and interactive teacher.

Keywords: Sport. Physycal Education. Vulnerability.

Evaluación del programa de capacitación para la formación sócio-educativa: el deporte como uma posibilidad para luchar contra la vulnerabilidade social

\section{Resumen}

La enseñanza del deporte puede ser utilizado como estratégia de afrontamiento de la vulnerabilidad social, ya que los maestros estén debidamente capacitados. Este trabajo analizado un programa de capacitación ofrecido a los profesores de Educación Física em El município de Uberaba - MG. En el estudio participaron 33 maestros y estudiantes de Educación Física que participaron en un programa de capacitación que se dividió en 05 talleres de 04 horas. Antes de que el primer taller, se administró un cuestionario a los participantes en la investigación, que contiene 08 preguntas abiertas sobre los temas que se trabajaron en los talleres. Y al final del último taller, se vuelve a aplicar para la comparación.Entre los participantes, el $85 \%$ asistió a todos los talleres, $68,29 \%$ tenían um promedio cambio en los conceptos de aprendizaje, lá mayoría tênia 3-5 respuestas positivas al cambio, y el concepto que más câmbios há sido la causa de la vulnerabilidad. Esto demostró que la educación continua es uma de lãs mejores posibilidades para la formación del profesorado y la calidad de la educación, respectivamente, debido a la exigência de un mayor contexto, el maestro participativo y interactivo.

Palabras clave: Deporte. Educación Física. La vunerabilidad.

\section{Referências}

ASSIS, S. Reinventando o Esporte: possibilidades da prática pedagógica. Campinas: Autores Associados, 2001.

BARBIERI, C. A. S. Esporte educacional: uma possibilidade de restauração do humano no homem.Canoas: Ulbra, 2001.

BETTI, M. Educação Física e sociedade. São Paulo: Movimento, 1992.

BOURDIEU, P. Coisas ditas. São Paulo: Brasiliense, 1990.

BRACHT, V. Sociologia crítica do esporte: uma introdução. Ijuí: Unijuí, 2003.

BRASIL. Secretaria Especial dos Direitos Humanos. Parâmetros para formação do socioeducador: uma proposta inicial para reflexão e debate, 2006. 
BURSZTYN, M. Da pobreza à miséria, da miséria à exclusão: o caso das populações de rua. In: BURSZTYN, M. No meio da rua: nômades, excluídos e viradores. Rio de Janeiro: Garamond, 2000. p. 27-55.

DEMO, P. Conhecimento e Aprender: sabedoria dos limites e desafios. Porto Alegre: Artmed, 2000.

ESTEVE, J. M. Mudanças sociais e função docente. In: NÓVOA, A. Profissão professor. Porto: Porto, 1995. p. 93-124.

FERREIRA, N. T. O Esporte na formação do cidadão. In: Memórias: Conferência Brasileira de Esporte Educacional. Rio de Janeiro: Gama Filho, 1996.

GONTIJO, D. T.; MEDEIROS, M. Crianças e adolescentes em situação de rua: contribuições para a compreensão dos processos de vulnerabilidade e desfiliação social. Revista Ciência e Saúde Coletiva, v. 14, n. 2, 2009.

GÜNTHER, M. C.; MOLNA NETO, V. Formação permanente de professores de Educação Física na rede municipal de ensino de Porto Alegre: uma abordagem etnográfica. Revista Paulista de Educação Física, São Paulo, v. 1, n. 14, p. 72-84, 2000.

HARGREAVES, A. Aprendendo a mudar: o ensino para além dos conteúdos e da padronização. Porto Alegre: Artmed, 2000.

MINAYO, M. C. S. Ciência, técnica e arte: o desafio da pesquisa social. In: MINAYO, M. C. S. Pesquisa social: teoria, método e criatividade. 10. ed. Petrópolis: Vozes, 1998. p. 9-30.

NÓVOA, A. (Coord.). Os professores e sua formação. Lisboa: Dom Quixote, 1997.

PRONI, M.; LUCENA, R. Esporte: história e sociedade. Campinas: Autores Associados, 2002.

PROETI. Programa de educação de tempo integral (PROETI). Disponível em: <http://www.uberaba.mg.gov.br/smel/index.php?option $=$ com_content $\&$ task $=$ view $\& \mathrm{id}=22 \&$ Itemid $=26>$. Acesso em: 16 maio 2009 . 
SAGRILLO, D. R.; BACCIN, E. V.; BOTH, V. J. Políticas públicas de esporte e lazer: análise do programa de esporte e lazer na cidade. In: Congresso Brasileiro de Ciências do Esporte. Anais. Porto Alegre, CBCE, 2005, p. 1-8.

SOUZA, J. R. S. Formação continuada em serviço: ressignificando a prática docente. In: Seminário Nacional de Pedagogia Universitária. Anais. Porto Alegre: PUCRS, 2006. 1 CD-ROM.

TARDIF, M. \& LESSARD, C. O trabalho docente: elementos para uma teoria da docência como profissão de interações humanas. Petrópolis: Vozes, 2004.

TUBINO, M. O Esporte no Brasil: do período colonial aos nossos dias. São Paulo: Ibrasa, 1996.

; GARREDO, F. \& TUBINO, F. Dicionário Enciclopédico

Tubino do Esporte. Rio de Janeiro: Senac, 2007.

Recebido em: 19/08/2011

Revisado em: 19/12/2011

Aprovado em: 16/03/2012

Endereço para correspondência

alinedessupoio@bol.com.br

Aline Dessupoio Chaves

Universidade Federal do Triângulo Mineiro

Rua Guilherme Ferreira $6503^{\circ}$ andar

Centro

38065-000 - Uberaba, MG - Brasil 